[Agr. Biol. Chem., Vol. 32, No. 2, p. 225 233, 1968]

\title{
Thermal Inactivation of Myosin A-Adenosine Triphosphatase in the Presence of F-Actin
}

\author{
By Tsutomu Yasur, Hideyuki Kawakami and Fumi Morita ${ }^{*}$ \\ Department of Animal Science, Faculty of Agriculture \\ Hokkaido University, Sapporo \\ * Department of Chemistry, Faculty of Sciences, \\ Hokkaido University, Sapporo \\ Received August 31, 1967
}

\begin{abstract}
The influence of the concentration of F-actin on the inactivation of myosin A-ATPase in solution and in suspension has been studied. The reaction departs from typical firstorder behavior in that the rate decreases as the reaction proceeds. The extent of this effect varied greatly with the amount of $\mathrm{F}$-actin added and slightly with $\mathrm{pH}$ and ionic strength. The interpretation of the experimental results is discussed. A kinetic mechanism which qualitatively accounts for the observed behavior and which suggests the occurrence of two types of actomyosin complexes with respect to susceptibility to denaturation is proposed.

The rate of denaturation of myosin A has been found to decrease greatly on an addition of magnesium and also with a decrease in ionic strength at high (10.3) or low (6.0) $\mathrm{pH}$ values.
\end{abstract}

Evidence has been presented ${ }^{1 \sim 6 !}$ that the inactivation of myosin A-ATPase [EC 3.6.1.3, ATP phosphohydrolase] is a first-order reaction. In the presence of F-actin, however, the course of the reaction is not entirely typical of a first-order process, ${ }^{2,3,7,81}$ decreasing more rapidly as the reaction proceeds than is predicted by the first-order law.

An explanation of these deviations from

1) L. Ouellet, K.J. Laidler and M. F. Morales, Arch. Biochem. Biophys., 39, 37 (1952).

2) T. Yasui, T. Fukazawa, Y. Hashimoto, S. Kitagawa and A.T. Sasaki, J. Biochem., 45, 717 (1959).

3) T. Yasui, Y. Hashimoto and Y. Tonomura, Arch. Biochem. Biophys, , 87, 55 (1960).

4) G. E. Pelletier and L. Ouellet, Can. J. Chem., 39, 265 (1961).

5) K. Takahashi, T. Yasui, Y. Hashimoto and Y. Tonomura, Arch. Biochem. Biophys., 99, 45 (1963). 6) T. Yasui, J. Morita and K. Takahashi, J. Biochem., 60, 303 (1966).

7) Y. Yudasaka, Seitai no Kagaku, 7, $26 \mathrm{I}$ (1956).

8) K. Maruyama and Y. Ishikawa, J. Biochem., 57, $712(1965)$. first-order behavior is essential if we hope to understand the chemical nature of the reactions and the structure and stabilizing forces of the region of myosin $\mathrm{A}$ combining with actin.

In the present investigation we have studied the effects of actin concentrations on the inactivation reaction of myosin A-ATPase at varying $\mathrm{pH}$ values and ionic strengths. A kinetic mechanism compatible with the experimental results is presented in this paper.

\section{MATERIALS AND METHODS}

Materials. Myosin A was extracted from rabbit skeletal muscle with Guba-Straub solution for $15 \mathrm{~min}$ at $4^{\circ} \mathrm{C}$ and prepared according to the method described by Perry $^{91}$ with slight modifications. ${ }^{10}$

9) S. V. Perry, "Methods in Enzymology", Vol. II, ed. by S. P. Colowick and N. O. Kaplan, Academic Press Inc., New York, 1955, p. 582.

10) X. Tonomura, S. Tokura, K. Sekiya and K. Imamura, Arch., Biochem. Biophys., 95, 229 (1961). 
Actin was prepared by the method of Mommaerts.11,12) The crude cold extract (at $0^{\circ} \mathrm{C}$ ) was clarified by centrifugation at $70,000 \times \mathrm{g}$ for $1 \mathrm{hr}$. It was purified by polymerization (in $0.1 \mathrm{M} \mathrm{KCl}$ ) followed by high speed centrifugation and depolymerization by dialysis against $0.2 \mathrm{mM}$ ATP and $1 \mathrm{mM}$ borateborax buffer $\left(\mathrm{pH} 8.3\right.$ ) for 2 days at $3^{\circ} \mathrm{C}$. Before use the G-actin was transformed into the F-form in $0.1 \mathrm{M} \mathrm{KCl}$.

Myosin B was extracted from rabbit muscle with Weber-Edsall solution containing $1 \mathrm{mM}$ EDTA for 24 hr and purified three times by the usual dilutionprecipitation method. Two hour-extracted myosin B was obtained by Ebashi's method ${ }^{13}$ ) with slight modifications. Homogenized rabbit muscle was extracted with 3 volumes of $0.6 \mathrm{M} \mathrm{KCl}$ at $0^{\circ} \mathrm{C}$ for $2 \mathrm{hr}$. The extract was diluted with $0.2 \mathrm{mM} \mathrm{NaHCO}$ to $\mu=0.2$. The precipitate collected by centrifugation at 5100 $\times \mathrm{g}$ was redissolved in $0.6 \mathrm{M} \mathrm{KCl}$. The cycle of precipitation and redissolving was repeated for further purification.

All the stock solutions of these proteins were used within 10 days after preparation.

Procedure-ATPase measurements were performed in $0.5,0.14$ and $0.1 \mathrm{M} \mathrm{KCl}$ at $25^{\circ} \mathrm{C}$ and $\mathrm{pH} 7.8$ (tris-HCl) or 7.0 (tris-maleate). A $1.0 \mathrm{ml}$ sample of a myosin solution was pipetted into $9 \mathrm{ml}$ of a buffer with or without an adequate amount of modifer and incubated in a constant temperature bath at $25^{\circ} \mathrm{C}$. ATP was always added in excess $(1 \mathrm{~mm})$. The hydrolysis reaction was followed by pipetting at measured intervals of time $2 \mathrm{ml}$ samples of the reaction mixture into $2 \mathrm{ml}$ of a $12 \%$ solution of trichloroacetic acid, filtering the precipitated myosin, and determining inorganic phosphate concentrations in the filtrate by the Martin and Doty methodis) using a Hitachi EPU-2A spectrophotometer. The number of $\mu$ moles of inorganic phosphate produced per $\mathrm{mg}$ myosin per minute was taken as a measure of the enzyme activity.

The inactivation of myosin was studied by incubating a solution of the enzyme $(2 \mathrm{mg}$ protein $/ \mathrm{ml}$ )

11) W.F.H.M. Mommaerts, J. Biol. Chem., 55, $604(1952)$.

12) W.F.H.M. Mommaerts, "Hawk's Physiological Chemistry", 14th ed., McGraw-Aill Inc., New York, 1965 p. 231 .

13) S. Ebashi and F. Ebashi, J. Biochem., 55, 604 (1964).

14) J.B. Martin and D. M. Doty, Anal. Chem., 21, 965 (1949). in a buffer of the required $\mathrm{pH}$ and ionic strength at $35^{\circ} \mathrm{C}$ and following its loss of activity with time. A flask containing buffer (tris or glycine) with or without $\mathrm{F}$-actin was placed in a constant temperature bath. A stock solution of myosin A or myosin B was added so as to make the mixture contain $2 \mathrm{mg}$ myosin/ml and the resulting mixture thoroughly mixed by swirling of the flask. At measured intervals of time, the ATPase activity of each sample was then measured as described previously.

F-Actin was modified by 2,4,6-trinitrobenzenesulfonate by the method of Tonomura et al.15) Trinitrobenzenesulfonate solution, adjusted to $\mathrm{pH} 8.2$, was added to $\mathrm{G}$-actin at $\mathrm{pH} 8.2$ and $2^{\circ} \mathrm{C}$. The molar ratio of trinitrobezenesulfonate to G-actin (M.W.= 61,000 ) was 30 . The $\mathrm{pH}$ of the mixture was maintained in the range of 8.2 to 8.4 by $0.2 \mathrm{M}$ tris. After $200 \mathrm{~min}$ the $\mathrm{pH}$ of the reaction mixture was adjusted to 7.0 to slow down the velocity of binding of trinitrobezenesulfonate to $\mathrm{G}$-actin. The G-actin was then transformed into the $F$-form by an addition of $0.1 \mathrm{M} \mathrm{KCl}$. It was reported ${ }^{15}$ ) that $\mathrm{G}$-actin thus treated binds with $I \sim 2$ moles of the reagent and can be transformed into the F-form but loses its ability to bind with myosin A.

Viscosity was measured with an Ostwald type viscometer of $4 \mathrm{ml}$ capacity having a flow time of approximately 30 seconds for $0.5 \mathrm{M} \mathrm{KCl}$ containing $20 \mathrm{mM}$ tris buffer $(\mathrm{pH} 7.8)$ at $20^{\circ} \mathrm{C}$.

Turbidity was determined by measuring absorption at $360 \mathrm{~m} \mu$ with a Hitachi EPU-2A spectrophotometer.

Protein was determined by the biuret procedure standardized with Kjeldahl nitrogen determinations.

Samples for electron microscopic observation was prepared as reported previoulsy with slight modification.6) After being rinsed with $0.6 \mathrm{M} \mathrm{KCl}$ alone, the myosin solution $(0.1 \mathrm{mg} / \mathrm{ml})$ on carbon film was negatively stained by floating on $0.3 \%$ uranyl acetate. By this technique, we have been able to observe myosin aggregates formed during the course of denaturation even in $0.6 \mathrm{M} \mathrm{KCl}$, though they failed to show up under the electron microscope ${ }^{6)}$ with the formalin fixation technique.16) A Hitachi 11-B Electron Microscope was used with a $30 \mu$ objective aperture and an accelerating voltage of $75 \mathrm{kV}$.

15) Y. Tonomura, S. Tokura and K. Sekiya, $J$. Biol. Chem., 237, 1074 (1962).

16) H. E. Huxley, J. Mol. Biol., 7, 281 (1963). 


\section{RESULTS}

\section{The effect of $\mathbf{F}$-actin}

Previous results ${ }^{2,3,6,71}$ had shown that the degree of thermal inactivation of myosin A-ATPase was influenced markedly when examined in the presence of F-actin. Accordingly, the course of the inactivation was investigated at a series of F-actin concentrations at $35^{\circ} \mathrm{C}$ and $\mathrm{pH}$ 7.8. The results are given in Figs. $1 \sim 3$. In Fig. 3 , as in Figs. 4 and 6 , the curves represent the theoretical formulation advanced in the Discussion.

As clearly shown in Fig. 1 (a), the rate of denaturation of myosin $\mathrm{A}$ at the beginning of the reaction decreases as the amount of $\mathrm{F}$-actin increases. When the weight ratio of myosin A to F-actin becomes lower than $5: 1$, no inactivation is observable within $2 \mathrm{hr}$.

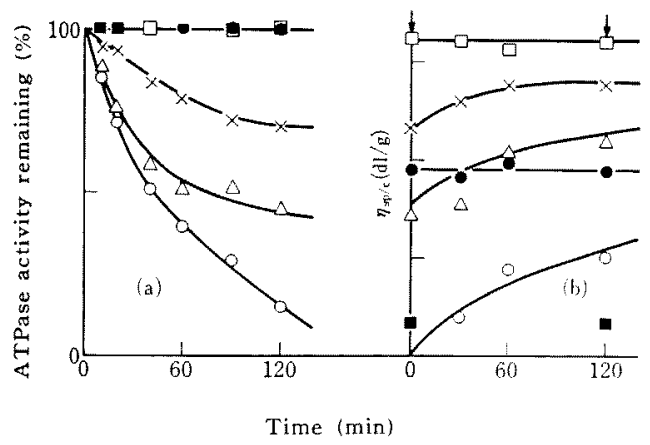

F1G. 1. Inhibitory Effect of F-Actin on the Denaturation of Myosin A.

Myosin A $(2.0 \mathrm{mg} / \mathrm{ml})$ was incubated at $35^{\circ} \mathrm{C}$

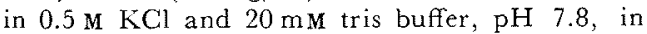
the presence or absence of Factin. Activity was measured (a) at $\mathrm{pH} 7.8$ and $25^{\circ} \mathrm{C}$ and in $0.5 \mathrm{M}$ $\mathrm{KCl}, 20 \mathrm{~mm}$ buffer, $5 \mathrm{~mm} \mathrm{CaCl} 2$ and $1 \mathrm{~mm} \mathrm{ATP}$. Viscosity measurements (b) were made at $20^{\circ} \mathrm{C}$ in $0.5 \mathrm{M} \mathrm{KCl}$ and $20 \mathrm{~mm}$ buffer, $\mathrm{pH} \mathrm{7.8.} \mathrm{-O-:}$ myosin A, - - : myosin B, $\triangle \triangle$ : myosin $A+F$-actin (weight ratio of myosin $A$ to $F$-actin $=10: 1$ ), - $x$-: myosin $\mathrm{A}+\mathrm{F}$-actin (weight ratio of myosin $A$ to $F$-actin=7.5:1), $\quad \square-$ : myosin $A+F$-actin (weight ratio of myosin $A$ to $F$-actin $=5: 1$ ). Arrows in (b) indicate the addition of ATP (final conc. $1 \mathrm{mM}$ ) with $\mathrm{MgCl}_{2}$ (final conc. $5 \mathrm{mM}$ ) at these points. Viscosity exhibited after the addition of ATP is shown by the symbol (घ).

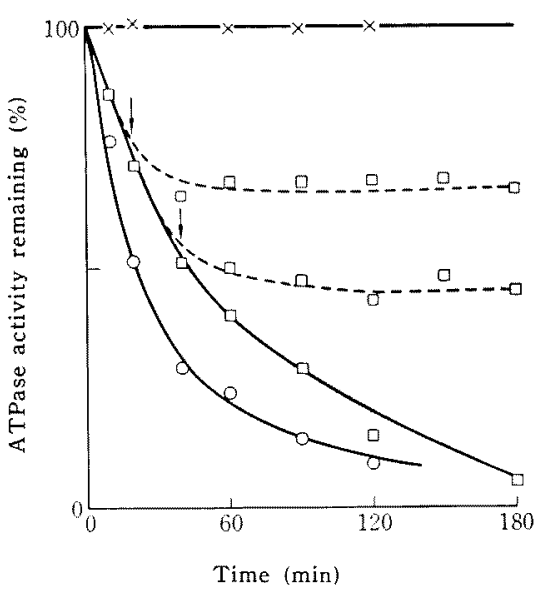

FIG. 2. Inhibitory Effect of Normal and Trinitrobenzenesulfonate-treated F-Actin on the Denaturation of Myosin A.

Conditions for incubation and activity measurements were the same as in Fig. 1. - $-x-$ : myosin $\mathrm{A}+\mathrm{F}$-actin, - $\mathrm{O}-$ : myosin $\mathrm{A}+$ trinitrobenzenesulfonate-treated F-actin, $-\square-$ myosin A, at the points indicated by arrows F-actin was added to the incubation system. In this experiment, whight ratio of myosin A to F-actin was $3: 1$.

Concomitant studies on changes in viscosity are shown in Fig. 1(b), in which the degree of increase in viscosity decreases as the amount of F-actin increases. The fact that myosin $\mathrm{A}$ is prevented by $\mathrm{F}$-actin from thermal denaturation is further supported by the results shown in Fig. 2. At any stage during the course of the reaction, the addition of $F$-actin to myosin $\mathrm{A}$ (weignt ratio of myosin $\mathrm{A}$ to $\mathrm{F}$-actin $=3: 1$ ) was found to interupt completely the denaturation of myosin A. On the other hand, the trinitrobenzenesulfonate-treated F-actin exhibited no protective effect, but rather accelerated the reaction (Fig. 2). In Figs. 3, 4 and 6, logarithmic fraction of the original ATPase activity is plotted against time. The reaction deviates from a simple first-order behavior, and the degree of deviation is influenced appreciably by the concentration of F-actin. Each of the curves, however, shows a definite tendency to approach linearity after 
the initial curved portion. It appears, therefore, that the course of thermal denaturation of myosin $\mathrm{A}$ in the presence of F-actin consists of two first-order reactions. From equation (6) in the scheme proposed later (see Discussion) respective values for the first slope $\left(K_{3}{ }^{\prime}\right)$ and the second one $\left(K_{4}{ }^{\prime}\right)$ in Fig. 3 were calculated and listed in Table I. $K_{3}{ }^{\prime}$ decreases as $\mathrm{F}$-actin concentration increases, whereas $K_{4}{ }^{\prime}$ displays a maximal value (Fig. 3 and Table I).

\section{Effect of $\mathrm{pH}$}

Although the denaturation of myosin A (2 $\mathrm{mg} / \mathrm{ml})$ is almost completely inhibited by the addition of $\mathrm{F}$-actin $(0.4 \mathrm{mg} / \mathrm{ml})$ at neutral $\mathrm{pH}$, the inhibitory effect is incomplete if the $\mathrm{pH}$ value of the incubation system is shifted towards the acidic ( $\mathrm{pH} 6.0$ ) or alkaline $(\mathrm{pH}$ 10.3) side (Fig. 4). The phenomenon was

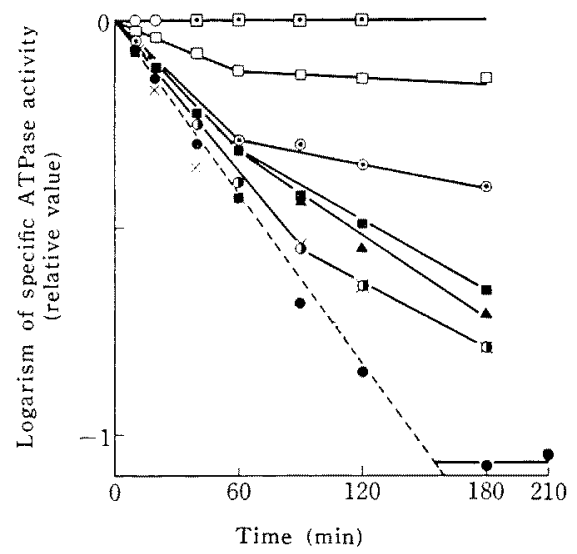

FIG. 3. Logarithm of the Activity of Myosin A as a Function of Time in the Presence of Various Concentrations of F-actin.

Conditions for incubation and activity measurements were the same as in Fig. 1.

_..: Weight ratio of myosin A to $\mathrm{F}$-actin $=1: 0$.

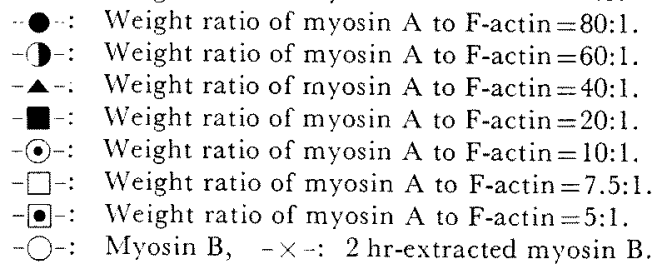

also true with the case of $24 \mathrm{hr}$-extracted myosin B whose main component has been found to be actomyosin. ${ }^{17}$

It has been shown that denatured myosin A loses its morphological characteristics at low ionic strength and forms a random network system ${ }^{61}$ resulting in an increase in turbidity. Since the actomyosin complex is known to dissociate into myosin $\mathrm{A}$ and $\mathrm{F}$-actin in the presence of $\mathrm{MgCl}_{2}$ and $\mathrm{ATP}$, the course of myosin A denaturation even in the presence of the actomyosin complex may possibly be followed by measuring the changes in turbidity at low ionic strength and neutral $\mathrm{pH}$ in the presence of $\mathrm{MgCl}_{2}$ and ATP. The results obtained indicated that turbidity increased at different rates with changes in $\mathrm{pH}$ as the reaction proceeded (Fig. 5).

\section{Table I. The apparent Rate Constant of DENATURATION OF MYOSIN A-ATPASE IN THE PRESENCE OF F-ACTIN AT $35^{\circ} \mathrm{C}$ pH 7.8 AND IN $0.5 \mathrm{M} \mathrm{KCl}$}

\begin{tabular}{|c|c|c|c|}
\hline $\begin{array}{c}\text { myosin } \\
\text { A : F-actin* }\end{array}$ & $\begin{array}{c}k_{3}^{\prime} \\
\left(\sec ^{-1}\right)^{* *}\end{array}$ & $\begin{array}{c}K_{3}^{\prime} \\
\left(\mathrm{sec}^{-1}\right)^{* * * *}\end{array}$ & $\begin{array}{c}K_{4}^{\prime} \\
\left(\sec ^{-1}\right)^{* * * *}\end{array}$ \\
\hline myosin A & $1.15 \times 10^{-4}$ & - & - \\
\hline myosin $B^{* * * * * *}$ & * $\quad-$ & $11.5 \times 10^{-5}$ & $3.89 \times 10^{-5}$ \\
\hline $80: 1$ & - & $11.5 \times 10^{-5}$ & 0 \\
\hline $60: 1$ & - & $10.4 \times 10^{-5}$ & $4.26 \times 10^{-5}$ \\
\hline $40: 1$ & - & $9.6 \times 10^{-5}$ & $4.64 \times 10^{-5}$ \\
\hline $20: 1$ & - & $9.5 \times 10^{-5}$ & $4.17 \times 10^{-5}$ \\
\hline $10: 1$ & - & $9.0 \times 10^{-5}$ & $1.46 \times 10^{-5}$ \\
\hline $7.5: 1$ & - & $2.7 \times 10^{-5}$ & $0.91 \times 10^{-5}$ \\
\hline $5: 1$ & - & 0 & - \\
\hline $2: 1$ & - & 0 & - \\
\hline myosin B & - & 0 & - \\
\hline
\end{tabular}

Conditions were the same as in Fig. 1.

* Weight ratio of myosin A to F-actin

** $\quad k_{3}{ }^{\prime}=\frac{k_{3}}{2.303}(c . f \cdot$ discussion $)$

$* * * \quad K_{3}{ }^{\prime}=\frac{K_{3}}{2.303}(c . f$. discussion $)$

$* * * * \quad K_{4}^{\prime}=\frac{K_{4}}{2.303}(c . f$. discussion $)$

****** Two-hr extracted myosin $\mathrm{B}$

17) A. Szent-Gyorgyi, "Chemistry of Muscular Contraction", 2nd ed., Academic Press Inc., New York, 1952 , p. 72. 


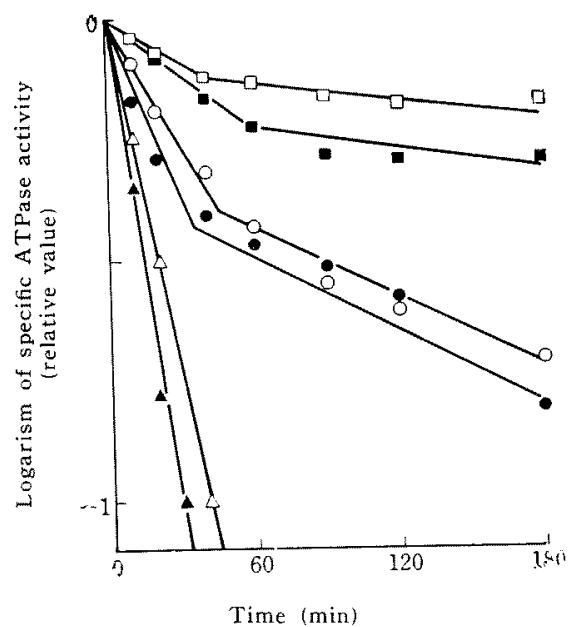

FIG. 4. Logarithm of the Activity of Myosin A and Myosin B as a Function of Time.

Incubation of myosins $(2.0 \mathrm{mg} / \mathrm{ml})$ was performed at $\mathrm{pH} 6.0$ and 10.3 in $0.5 \mathrm{M} \mathrm{KCl}$ and $20 \mathrm{mM}$ tris or glycine buffer. Activity measurements were the same as in Fig. 1.

- - Myosin A at $\mathrm{pH} 6.0$.

- $\triangle$-: Myosin A at $\mathrm{pH} 10.3$.

-1-: Myosin B at pH 6.0.

- - - Myosin B at $\mathrm{pH} 10.3$.

- - Myosin A+F-actin, at $\mathrm{pH}$ 6.0, weight ratio of myosin $A$ to $F$-actin $=5: 1$.

-O-: Myosin A+F-actin at $\mathrm{pH} 10.3$, weight ratio of myosin $A$ to $F$-actin $=5: 1$.

Preliminary electron microscopic studies on the denaturation of $24 \mathrm{hr}$-extracted myosin $\mathrm{B}$ at varying $\mathrm{pH}$ values indicated that at $\mathrm{pH}$ 7.8 no detectable change in morphology in $0.6 \mathrm{M} \mathrm{KCl}$ was observed before or after the reaction. At $\mathrm{pH} 6.0$ and 10.3 , however, shrunken free actin filaments were seen after reaction for $180 \mathrm{~min}$.

\section{Effect of ionic strength}

At low ionic strength $(0.14 \mathrm{~m} \mathrm{KCl})$, less $\mathrm{F}$ actin is needed to protect against the denaturation of myosin A than at high ionic strength $(0.5 \mathrm{M} \mathrm{KCl})$ (Fig. 6(a)). The addition of Factin in an amount equal to 0.13 time the weight of myosin $\mathrm{A}$ (weight ratio of myosin A to F-actin of $7.5: 1$ ) was enough for complete inhibition. In $0.5 \mathrm{M} \mathrm{KCl}$ the rates of myosin
A denaturation at $\mathrm{pH} 6.0,7.0$ and 10.3 have been found to be $5.50 \times 10^{-4} \mathrm{sec}^{-1}, 1.6510^{-4}$ $\mathrm{sec}^{-1}$, and $4.17 \times 10^{-4} \mathrm{sec}^{-1}$, respectively, whereas they are $2.22 \times 10^{-4} \mathrm{sec}^{-1}, 1.10 \times 10^{-4} \mathrm{sec}^{-1}$, and $1.33 \times 10^{-4} \mathrm{sec}^{-1}$ in $0.14 \mathrm{M} \mathrm{KCl}$ under identical conditions (Tables II and III).

The rate of denaturation of myosin $\mathrm{A}$ decreases greatly with decrease in ionic strength at high or low $\mathrm{pH}$ values and to a lesser extent at neutral $\mathrm{pH}$. In $0.14 \mathrm{~m} \mathrm{KCl}$ myosin $\mathrm{B}$ is less susceptible to denaturation, and the accelerating effect of low or high $\mathrm{pH}$ on the reaction is slight (Figs. 4 and $6(\mathrm{~b})$ ). When measured within $120 \mathrm{~min}$, a decrease in the rate of denaturation is also brought about by the addition of $\mathrm{MgCl}_{2}$ but not by $\mathrm{CaCl}_{2}$ ( Fig. 6 (a) and Table III). The presence or absence of either $\mathrm{MgCl}_{2}$ or $\mathrm{CaCl}_{2}$ in the reaction mixture for the ATPase assay did not, however, cause changes in the rate of denaturation (Fig. 6 (a) and Table III). The cause of the deviations seen after prolonged incubation from first-order behavior in the presence of divalent metal ions is not known at the moment and further studies are now in progress. However, the inhibitory effect of $\mathrm{MgCl}_{2}$ on the denaturation of myosin-ATPase is consistent with earlier reports. ${ }^{7,8}$ These results may be related to an associative property of native myosin $A$ which has been suggested to play an important part in preventing the protein from denaturation and which deserves further study.

\section{DISCUSSION}

The addition of $\mathrm{F}$-actin to myosin $\mathrm{A}$ in solution results in the formation of an actomyosin complex whose morphological feature has been called the arrow head structure. ${ }^{161}$ However, the mode of interaction between those two proteins has also been known to depend very much on experimental conditions, i.e., high or low $\mathrm{pH}$ favors dissociation ${ }^{15,18}$

18) J.J. Blum, Arch. Biochem. Biophys., 43, 176 (1953). 


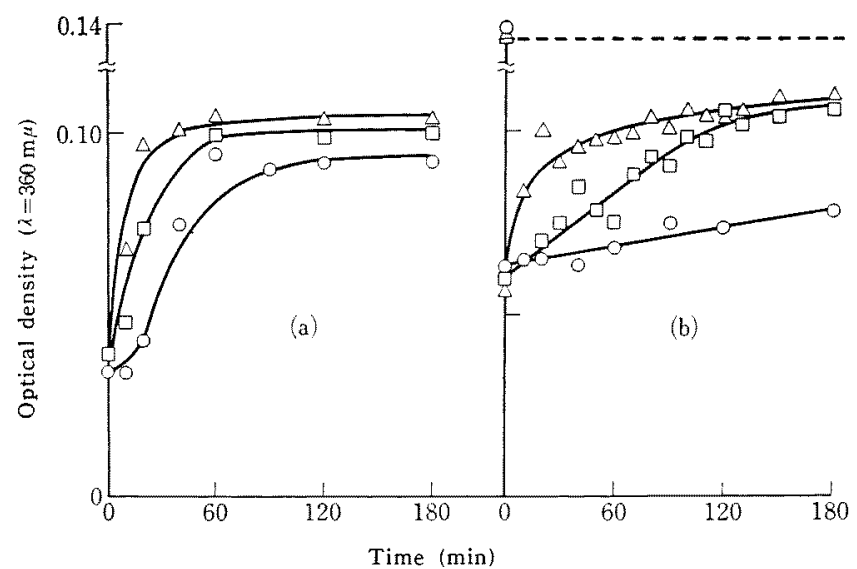

FIG. 5. Changes in Turbidity during the Course of Denaturation of Myosin A (a) and Myosin B (b).

Conditions for denaturation were the same as in Figs. I and 4, and those for turbidity measurement were the same as those for ATPase assay in Fig. 6 except $5 \mathrm{mM} \mathrm{MgCl} 2$ was used throughout. Turbidity was expressed as the increase in optical density at $360 \mathrm{~m} \mu$ (turbidity at zero angle).

(a) -O-: pH 7.8, - $\square-$ : pH 10.3, $-\triangle-$ : pH 6.0.

(b) $-\bigcirc-$ : pH 7.8, - $\square-$ : pH 10.3, - $\triangle$-: pH 6.0 .

A dotted line indicates the turbidity of native myosin

$B$ in the absence of $1 \mathrm{mM}$ ATP.

Table II. The apparent Rate Constants of Denaturation of Myosin A-A tPase in the Presence of F-aCtin at $35^{\circ} \mathrm{C}$ in $0.5 \mathrm{M} \mathrm{KCl}$ and at $\mathrm{pH}$

VALUES OF $6.0,7.0$ AND 10.3

Buffer $(\mathrm{pH})$

Tris-maleate

$(7.0)$

Tris-maleate

(6.0)

Glycine-KOH (10.3)

$$
\begin{aligned}
& \text { Myosin A : F-Actin } \\
& \text { myosin } A^{*} \\
& \text { myosin } B \\
& \text { myosin A } \\
& 5: 1 \\
& \text { myosin B } \\
& \text { myosin A } \\
& 5: 1 \\
& \text { myosin B }
\end{aligned}
$$

$K_{3}^{\prime}\left(\sec ^{-1}\right)^{* * *}$

$1.65 \times 10^{-4}$

$5.50 \times 10^{-4}$

$4.17 \times 10^{-4}$

\section{0}

$$
\begin{array}{r}
19.4 \times 10^{-5} \\
7.1 \times 10^{-5}
\end{array}
$$

$$
14.6 \times 10^{-5}
$$$$
3.9 \times 10^{-5}
$$

Conditions were the same as in Fig. 4.

* ATPase measurement was made at pH 7.0 and $20^{\circ} \mathrm{C}$.

** For $k_{3}{ }^{\prime}, K_{3}{ }^{\prime}$ and $K_{4}{ }^{\prime}$, see Table $\mathbf{I}$.

and low ionic strength associatian. ${ }^{15}$ The present work indicates that in the presence of $\mathrm{F}$-actin the inactivation of myosin $\mathrm{A}$ with time deviates from the typical first-order behavior (Figs. 3, 4 and 6). The deviation varies greatly with $\mathrm{F}$-actin concentration and, to a lesser extent, with $\mathrm{pH}$ and ionic strength.
It is reasonable to assume that myosin $\mathrm{A}$ interacts with $\mathrm{F}$-actin in stages before the inactivation takes place. It seems possible, therefore, that the inactivation would proceed by an entirely different mechanism than those reported in earlier experiments. ${ }^{2-6)}$

A different interpretation is thus suggested 


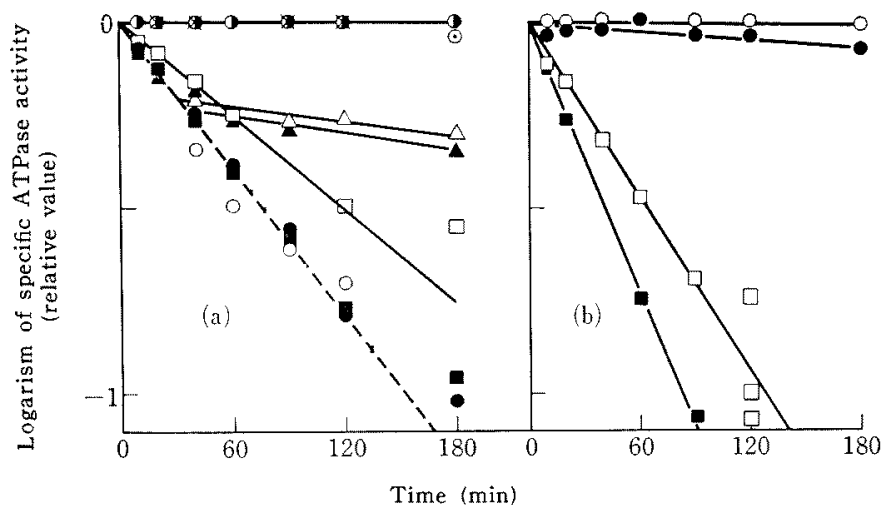

FIG. 6. Logarithm of the Activity of Myosin A and Myosin B as a Function of Time under Different Conditions.

ATPase measurements were performed at $\mathrm{pH} 7.0$ and $25^{\circ} \mathrm{C}$ and in $0.14 \mathrm{M} \mathrm{KCl}$ and $1 \mathrm{mM}$ ATP with or without divalent metals.

(a): Denaturation of moysin $\mathrm{A}$ at $\mathrm{pH} 7.0$ and $35^{\circ} \mathrm{C}$ in $0.14 \mathrm{M} \mathrm{KCl}$.

- : Myosin A whose activity was measured in the presence of $1 \mathrm{mM}$ $\mathrm{CaCl}_{2}$.

-1-: Myosin A whose activity was measured in the presence of $1 \mathrm{~mm}$ $\mathrm{MgCl}_{2}$.

- . -: Myosin A whose activity was measured without nodifier.

--: Myosin A incubated in the presence of $1 \mathrm{mM} \mathrm{CaCl}_{2}$. Its activity was measured in the presence of $1 \mathrm{mM} \mathrm{CaCl}$.

- $\square$ : Myosin A incubated in the presence of $1 \mathrm{~mm} \mathrm{MgCl}_{2}$. Its activity was measured in the presence of $1 \mathrm{mM} \mathrm{MgCl}$.

$-\triangle-$ : Myosin A +F-actin (weight ratio of myosin $A$ to $F$-actin $=10: 1$ ) The activity was measured in the presence of $1 \mathrm{mM} \mathrm{MgCl}_{2}$.

- - - The same as above except that the activity was measured in the presence of $1 \mathrm{mM} \mathrm{CaCl}$.

$-x-$ : Myosin A F-actin (weight ratio of myosin $\mathrm{A}$ to $\mathrm{F}$-actin=7.5:1). The activity was measured in the presence of $1 \mathrm{mM} \mathrm{MgCl}$.

- - - The same as above except that the activity was measured in the presence of $1 \mathrm{mM} \mathrm{CaCl}$.

- - Myosin B. The activity was measured in the presence of $1 \mathrm{~mm}$ $\mathrm{CaCl}_{2}$.

(b) Denaturation of myosin $\mathrm{A}$ at $\mathrm{pH} 6.0$ (- - ) and $10.3(-\square-)$ in $0.14 \mathrm{M}$ $\mathrm{KCl}$ and that of myosin $\mathrm{B}$ at $\mathrm{pH} 6.0(--)$ and $10.3(-\mathrm{O}-)$ under the same conditions. One $\mathrm{mM} \mathrm{CaCl}_{2}$ was used in the ATPase assay.

in the concept that in the presence of F-actin a myosin A molecule may undergo denaturation in a number of different ways. Some of these may involve an unfolding of the ATPase site on the free myosin A molecules with consequent inactivation, ${ }^{4,51}$ while others may involve stabilization of the site by reversible interactions of myosin $\mathrm{A}$ molecules with actin molecules. It turns out that the particular formulation of this concept is qualitatively consistent with our data, though the actual system is not so homogeneous as we may assume. A mathematical interpretation can be represented in the following way:

$$
\begin{gathered}
\mathrm{M}+i \mathrm{~A} \underset{k_{-1}}{\stackrel{k_{1}}{\rightleftarrows}} \mathrm{MA}_{i} \\
\mathrm{MA}_{i}+j \mathrm{~A} \underset{k_{-2}}{\stackrel{k_{2}}{\rightleftarrows}} \mathrm{MA}_{i+j}
\end{gathered}
$$


Table III. The ApParent Rate Constants of Denaturation of Myosin A-ATPase IN THE PRESENCE of F-ACTIN AT $35^{\circ} \mathrm{C}$ IN $0.14 \mathrm{M} \mathrm{KCl}$ AND AT $\mathrm{pH}$

VALUES OF $6.0,7.0$ AND 10.3

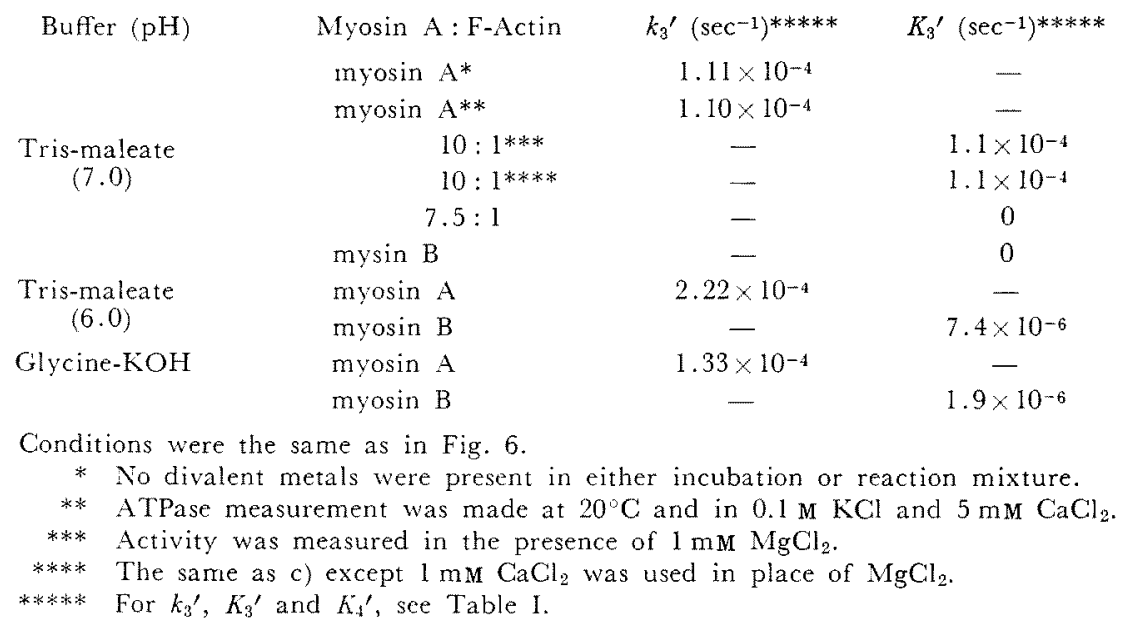

$$
\mathrm{M} \frac{k_{3}}{\mathrm{MA}_{i} \frac{k_{4}}{-} \mathrm{IA}_{i}}
$$

Here $M$ represents native myosin $A$, A represents the actin monomer, $\mathrm{MA}_{i}$ and $\mathrm{MA}_{j}$ stand for F-actomyosin complexes in which a myosin A molecule binds to $i$ and $j$ actin molecules $(1 \leqq i \leqq j$ ), respectively, and $I$ and $\mathrm{IA}_{i}$ represent denatured myosin $\mathrm{A}$ and actomyosin $\left(\mathrm{MA}_{i}\right)$, respectively. Transformations among these three species of ATPases proceed according to the specific rate constants, $k_{1}$, $k_{-1}, k_{2}$ and $k_{-2 .}$

By assuming that only $\mathrm{M}$ and $\mathrm{MA}_{i}$ undergo denaturation with different rate constants $k_{3}$ and $k_{+}$, respectively, that $\mathrm{MA}_{i-j}$ is roughly equivalent to native actomyosin, and that the complex-forming ability of myosin A with F-actin does not change much before or after denaturation the over-all rate of the denaturation will be given by

$$
\frac{d\left([\mathrm{I}]+\left[\mathrm{IA}_{i}\right]\right)}{d t}=[\mathrm{M}] k_{3}+\left[\mathrm{MA}_{i}\right] k_{4}
$$

where $[\mathrm{I}],\left[\mathrm{IA}_{i}\right],[\mathrm{M}]$ and $\left[\mathrm{MA}_{i}\right]$ represent the concentrations of each molecular species and $t$ is the reaction time. On the basis of the reactions in equations (1) to (4), the integration of equation (5) gives the following:

$$
I n^{\frac{\mathrm{m}-\left([\mathrm{I}]+\left[I \mathrm{~A}_{i}\right]\right)}{\mathrm{m}}}=-\left(K_{3} t+K_{4} t\right)
$$

where

$$
\begin{aligned}
& K_{3}=\frac{k_{3}}{1+\frac{k_{1}}{k_{-1}}[\mathrm{~A}]^{i}+\frac{k_{2}}{k_{-2}}[\mathrm{~A}]^{i+j}} \\
& K_{4}=\frac{k_{4}}{\left.1+\frac{k_{-1}}{k_{1}} \cdot 1 \mathrm{~A}\right]^{i}+\frac{k_{2}}{k_{-2}}[\mathrm{~A}]^{j}}
\end{aligned}
$$

Here, $m$ and $[A]$ denote concentrations of total myosin $A$ and free actin, respectively. These equations predict that if [A] increases, $K_{3}$ should decrease to zero and that if [A] decreases, $K_{3}$ should approach $k_{3}$, the first-order rate constant of the denaturation of myosin A. For $K_{4}$, the rate should show a maximum at a certain [A] and approach zero by either decreasing or increasing [A] from this point.

Although it is not possible to give actual values of $[A]$ in the system, it should increase with and increase in the amount of F-actin added. The results shown in Fig. 3 and Table I may therefore be reasonably explained by these equations. Results with $24 \mathrm{hr}-$ and $2 \mathrm{hr}$ extracted myosin B (Fig. 3 and Table I) also 
support the above view. Ionic strength $\mathrm{h}^{15}$ and $\mathrm{pH}$ values ${ }^{15,18 \text { ? }}$ may exert an influence over the rate constants in equations $(1) \sim(4)$. Thus various $K_{3}$ and $K_{4}$ values are obtained by changing experimental conditions (Figs. 4 and 6, Tables II and III). On the basis of the results with trinitrobenzenesulfonate treated F-actin, it is concluded that the protective action of $\mathrm{F}$-actin against denaturation of myosin $\mathrm{A}$ is achieved exclusively through the interaction of myosin $\mathrm{A}$ with actin.

The mechanism proposed here indicates that there are two types of actomyosin complexes with respect to susceptibility to denaturation.

It is of course possible that the deviation of the inactivation from a typical first-order reaction may be due to a heterogeneity of $\mathrm{F}$ actin which would yield actomyosin complexes with different dissociation constants. Attempts were made, therefore, to explain the data for actomyosin denaturation on this assumption. However, the hypothesis that heterogeneity of F-actin is the main reason for the peculiar kinetics of the reaction was discarded because the value of $K_{4}$ derived from the formulation of this hypothesis was found to increase with increase in F-actin concentration which is not consistent with the data.

Since the actomysin forming ability of myosin A remains constant ${ }^{19}$ during the course of inactivation or decreases much more slowly than that of ATPase inactivation, ${ }^{20221}$ our

19) G. Kaldror, J. Gitlin F. Westley and B.W. Volk, Biochemistry, 3, 1137 (1964).

20) B.F. Poglasov, "Structure and Functions of Contractile Proteins", Academic Press Inc., New York, 1966, p. 32.

21) M. Barany, K. Barany and $\mathrm{H}$. Oppenheimer, Nature, 1963, 694 .

22) S. V. Perry and J. Cotterill, Biochem. J., 92, $603(1964)$ assumption of the binding properties of myosin A ( $\mathrm{M}$ and $\mathrm{I}$ ) with $\mathrm{F}$-actin would be valid under our experimental conditions, especially at neutral $\mathrm{pH}$. The substance $\mathrm{MA}_{i-j}$ may be reasonably assumed to exist if the results of Tonomura et al. ${ }^{15)}$ and Gergely et al., ${ }^{231}$ who reported that the binding ratio of myosin A to F-actin was $3.7: 1$ by weight, are taken into consideration; the values of $i$ and $j$ are 1 in this case. The substance $\mathrm{MA}_{i}$, however, is at present hypothetical, and as yet there is no independent evidence for its existence. It might be the $\mathrm{G}$-actomyosin postulated by Rowe et $a .^{24,25)}$ or a complex or aggregated native myosin $\mathrm{A}$ with $\mathrm{F}$-actin.

Acknowledgement. The authors wish to thank Dr. K. Takahashi for performing the electron microscope study, and Drs. Y'uji Tonomura of Ohsaka University and H.O. Hultin of the University of Massachusetts for helpful advice and co-operation. This investigation was supported by a grant in aid for special project research on biophysics from the Ministry of Education of Japan, and by grants from Mishima Kaiun Science Foundation and the Ministry of Education of Japan.

23) J. Gergely and H. Kohler, "Conference on Chemistry of Muscle Contraction", Igaku Shoin, Tokyo, 1957 p. 14.

24) P. Johnson and A. J. Row, "Biochemistry of Muscle Contraction", ed. by John Gergely, Little Brown \& Co., Boston, 1964, p. 279.

25) E. Michaelyi and A.J. Rowe, Biochem. Z., 345, 267 (1966). 